\title{
Evaluation of cognitive impairment in patients with major depressive disorder in remission
}

\author{
Mustafa Ali, Magda Fahmy, Wafaa Haggag, Ashraf El-Tantawy and Haydy Hassan * (D)
}

\begin{abstract}
Background: Cognitive symptoms are one of the core symptoms of depressive disorders with a bearing effect on functional outcomes. Cognitive symptoms, including poor concentration and difficulty making decisions, are one of the DSM-IV diagnostic criteria for major depressive disorder. This study was designed to evaluate cognitive deficits in a sample of adult patients with major depressive disorder (MDD) in remission. A cross-sectional study was done on 60 patients fulfilling the diagnostic criteria of MDD in remission state. In addition, 60 normal subjects with matched age, sex, and educational level were compared with the patients group. Participants in both patients and control groups were subjected to clinical assessment using Mini-International Neuropsychiatric Interview plus (MINIplus), assessment of cognitive functions using Wechsler Memory Scale-Revised (WMS-R) short form, and Wisconsin Card Sorting Test (WCST).

Results: There were statistically significant differences between patients and control groups regarding cognitive function. The patients group scored less in visual memory, verbal memory, attention/concentration, and psychomotor speed. They also performed poorly regarding executive functions. But there was no statistically significant difference between the patients and control groups regarding sustained attention and visuospatial function. No significant correlations did exist between age at onset of MDD and the duration of illness with different domains of cognitive function except for figural memory of WMS-R and categories completed of Wisconsin card sorting test.
\end{abstract}

Conclusion: Patients with MDD in remission experienced deficits in several cognitive functions when compared to matched control subjects. The cognitive functions do not reach normal levels of performance, particularly in visual memory and executive functioning with remission of depressive symptoms.

Keywords: Major depressive disorder, Cognitive impairments

\section{Background}

Major depressive disorder (MDD) is the most common psychiatric disorders, with an estimated lifetime prevalence of $16 \%$ [1]. Its high prevalence and its major global impact, which are associated with considerable socioeconomic costs, characterize MDD. Thus, identification of factors associated with the course of illness and its functional outcome helps in designing treatment

* Correspondence: drhaydy@yahoo.com

Psychiatry and neurology Department, Faculty of Medicine, Suez Canal University, Ismailia City, Egypt

\section{Springer Open}

interventions, which reduce the individual and society burden [2]. Cognitive impairment (CI) during depression was identified as one factor predicting the relapse or recurrence of MDD and as a predictor of the functional outcome of depression $[3,4]$.

$\mathrm{CI}$ are found in the acute and remitted states of depression, despite pharmacological and psychotherapy interventions [5]. Cognitive symptoms are one of the main characteristics of depressive disorders with an influence on many functional outcomes. Poor concentration and difficult in decision-making are one of in the diagnostic 
Table 1 Socio-demographic variables

\begin{tabular}{|c|c|c|c|c|}
\hline Socio-demographic variables & Patients group $(n=60)$ & Control group $(n=60)$ & $t$ & $P$ \\
\hline Age (years) & & & 1.38 & 0.16 \\
\hline Mean \pm SD & $33 \pm 8.2$ & $34.9 \pm 7$ & & \\
\hline Sex & & & $x^{2}=0.03$ & 0.85 \\
\hline Male & $20(33.3 \%)$ & $21(35 \%)$ & & \\
\hline Female & $40(66.7 \%)$ & $39(65 \%)$ & & \\
\hline Educational level ( $n$ and \%) & & & $X^{2}=0.97$ & 0.6 \\
\hline$<6$ years & $2(3.3)$ & $2(3.3)$ & & \\
\hline $6-12$ years & $46(76.7)$ & $50(83.3)$ & & \\
\hline$>12$ years & $12(20)$ & $8(13.3)$ & & \\
\hline Marital status & & & $X^{2}=0.03$ & 0.85 \\
\hline Currently married & 31 (51.7\%) & $30(50 \%)$ & & \\
\hline Not married & 29 (48.3\%) & 30 (50\%) & & \\
\hline
\end{tabular}

There were statistically non-significant differences between patient and control groups regarding all socio-demographic variables $(p>0.05)$

criteria for major depression. Many cognitive functions impaired in MDD as attention, declarative memory, and executive function. Moreover, there was also accordant implication on working memory, attention and executive dysfunction, and processing speed [6]. It is now recognized that cognitive disorders are among the major causes of functional impairment in depressed patients. Cognitive symptoms should be considered important dimension of MDD and should be the target of any management action that is introduced [7].

\section{Aim of the study}

The aim of this study was to evaluate cognitive deficits in a sample of adult patients with MDD in remission.

\section{Methods}

This cross-sectional study was carried out on subjects attending regularly for follow-up at Outpatient Psychiatric Clinics, Neuropsychiatry Department, Suez Canal University Hospital, Ismailia Governorate, Egypt.

Table 2 Clinical variables of the patients group

\begin{tabular}{|c|c|}
\hline & $n=60$ \\
\hline \multicolumn{2}{|l|}{ Age at onset } \\
\hline Mean \pm SD & $23.3 \pm 6.3$ \\
\hline \multicolumn{2}{|c|}{ Duration of illness } \\
\hline Mean \pm SD & $8.4 \pm 4.99$ \\
\hline \multicolumn{2}{|c|}{ Number of episodes } \\
\hline Mean \pm SD & $3.87 \pm 1.96$ \\
\hline
\end{tabular}

\section{Subjects}

Patients group

A simple random sample of 60 patients who attended the outpatient psychiatric clinic in Suez Canal University Hospital aged from 18 to 45 years old and fulfill the diagnostic criteria of MDD in remission state according to DSM-IV. The study excluded patients who were on any medication that affects cognitive performance, received electro-convulsive therapy during the last 6 months, had neurological or medical disorders, or had substance use disorders.

\section{Control group}

Sixty subjects matched for age, sex, and educational level from blood bank donator who had no psychiatric, neurological, medical, or substance use disorders at the time of assessment were compared with the patients' group.

\section{Study procedure \\ Clinical assessment using the Arabic version of Mini- International Neuropsychiatric Interview plus (MINI-plus)}

A trained psychiatrist using MINI-plus applied to patients and control groups, which is a short structured clinical interview enabling researchers to make diagnoses of psychiatric disorders according to DSM-IV. The administration time of the interview is approximately 15 $\min [8]$.

\section{Assessment of cognitive functions}

1. Wechsler Memory Scale-Revised (WMS-R) short form. It is formed of a series of brief subtests, each measuring a different facet of memory. The seven subtests measure short-term learning and recall of both verbal and figural material. Figural stimuli are 
Table 3 Assessment of cognitive function by Wechsler memory scale

\begin{tabular}{|c|c|c|c|c|}
\hline WMS-R subtests & Patients group $(n=60)$ & Control group $(n=60)$ & $T$ & $P$ \\
\hline \multicolumn{5}{|l|}{ Visual memory } \\
\hline Figural memory, mean $\pm S D$ & $3.6 \pm 2.3$ & $9.9 \pm 1.7$ & 16.6 & $<0.001 \mathrm{HS}$ \\
\hline Visual paired associates, mean $\pm S D$ & $4.8 \pm 0.46$ & $4.97 \pm 0.1$ & 3.1 & 0.08 (NS) \\
\hline \multicolumn{5}{|l|}{ Verbal memory } \\
\hline Logical memory, mean $\pm S D$ & $3.5 \pm 1.4$ & $8.2 \pm 1.2$ & 19.5 & $<0.001(\mathrm{HS})$ \\
\hline Verbal paired associates, mean $\pm S D$ & $7.2 \pm 0.6$ & $10.2 \pm 1.4$ & 14.6 & $<0.001(\mathrm{HS})$ \\
\hline \multicolumn{5}{|c|}{ Attention/concentration/psychomotor speed function } \\
\hline Mental Control, mean \pm SD & $5.3 \pm 1.5$ & $8.4 \pm 1$ & 13 & $<0.001 \mathrm{HS}$ \\
\hline Digit span, mean $\pm S D$ & $5.2 \pm 1.4$ & $8.5 \pm 1$ & 13 & $<0.001(\mathrm{HS})$ \\
\hline \multicolumn{5}{|l|}{ Visuospatial function } \\
\hline Visual reproduction, mean $\pm S D$ & $5.5 \pm 0.5$ & $5.6 \pm 0.5$ & 1.8 & 0.08 (NS) \\
\hline
\end{tabular}

There were statistically significant differences between the patient and control groups. The patients' group scored less in cognitive functions regarding visual memory, verbal memory, attention/concentration, and psychomotor speed

presented visually and verbal stimuli are read to the examinee. The seven subtests contribute to the assessment of General Memory (five subtests) and Attention /Concentration/Psychomotor speed (two subtests) [9].

2. Wisconsin Card Sorting Test (WCST). It assesses conceptualization, abstract reasoning, and flexibility in problem-solving. Cards of different numbers, forms, and colors which are established by the examiner but unknown to the patient are presented to persons for sorting into groups. Many cognitive functions such as the ability to think abstractly, selectively attend, and shift cognitive set are acquired for successful performance on this test. In this study, a trained psychologist applied Sorting Test Computer Version 4-Research Edition to assess both patients and control groups [10].

\section{Statistical analysis}

Data are entered, checked, and analyzed by SPP for Windows version 8 and Epi-Info version 6.
For all abovementioned statistical tests done, the threshold of significance is fixed at a 5\% level ( $p$-value).

The following results were considered:

- Significant when the probability of error is less than $5 \%(p<0.05)$

- Non-significant when the probability of error is over $5 \%(p>0.05)$

- Highly significant when the probability of error is less than $0.1 \%(p<0.001)$

The smaller the $p$-value got, the more significant are the results.

\section{Results}

Discussion

While cognitive symptoms represent one of the core features of major depressive disorder, its persistence after recovery of depressive symptoms calls the attention of many researchers to study the pattern and reason for poor cognitive performance in a patient with MDD.

Table 4 Assessment of executive function by Wisconsin card sorting test

\begin{tabular}{|c|c|c|c|c|}
\hline Wisconsin card sorting test variables & Patients group $(n=60)$ & Control group $(n=60)$ & $T$ & $P$ \\
\hline \multicolumn{5}{|l|}{ Trial administered (conceptualization) } \\
\hline Mean \pm SD & $126.7 \pm 6.6$ & $109.2 \pm 19.7$ & 6.4 & $<0.001(\mathrm{HS})$ \\
\hline \multicolumn{5}{|l|}{ Categories completed (abstract thinking) } \\
\hline Mean \pm SD & $0.75 \pm 1.6$ & $5.2 \pm 1.4$ & 15.8 & $<0.001(\mathrm{HS})$ \\
\hline \multicolumn{5}{|l|}{ Perseverative errors (cognitive flexibility) } \\
\hline Mean \pm SD & $20.9 \pm 13.9$ & $14.5 \pm 6.8$ & 3.2 & $0.0017(\mathrm{~S})$ \\
\hline \multicolumn{5}{|c|}{ Failure to maintain set (sustained attention) } \\
\hline Mean \pm SD & $1.6 \pm 1.6$ & $1.46 \pm 1.3$ & 0.4 & 0.6 (NS) \\
\hline
\end{tabular}

There were statistically highly significant differences between patient and control groups regarding executive function with the patient group performed poor regarding trial administered (conceptualization) and categories completed (abstract ability) $(p<0.001)$ and also had a statistically significant higher percentage of perseverative errors (cognitive flexibility) $(p<0.05)$ 
Table 5 Correlation between duration of illness and cognitive and executive functions

\begin{tabular}{lll}
\hline & $\boldsymbol{r}$ & $\boldsymbol{P}$ \\
\hline Visual memory & -0.35 & $<0.001(\mathrm{HS})$ \\
$\quad$ Figural memory & 0.12 & $>0.05(\mathrm{NS})$ \\
$\quad$ Visual paired associates & & \\
Verbal memory & -0.1 & $>0.05(\mathrm{NS})$ \\
$\quad$ Logical memory & 0.04 & $>0.05(\mathrm{NS})$ \\
$\quad$ Verbal paired associates & & \\
Attention/concentration & -0.019 & $>0.05(\mathrm{NS})$ \\
$\quad$ Mental control & -0.16 & $>0.05(\mathrm{NS})$ \\
$\quad$ Digit span & & \\
Visuospatial function & -0.05 & $>0.05(\mathrm{NS})$ \\
$\quad$ Visual reproduction & & \\
Wisconsin card sorting test & 0.04 & $>0.05(\mathrm{NS})$ \\
$\quad$ Trial administered (conceptualization) & -0.28 & $<0.05(\mathrm{~S})$ \\
Categories completed (abstract ability) & -0.06 & $>0.05(\mathrm{NS})$ \\
Perseverative errors (cognitive flexibility) & -0.18 & $>0.05(\mathrm{NS})$ \\
Failure to maintain set (sustained attention) &
\end{tabular}

There were statistically non-significant correlations between duration of illness and different subsets of Wechsler memory scale $(p>0.05)$, except for figural memory (a subtest of visual memory) which exhibited statistically a high significant correlation with duration of illness $(p<0.001)$ though this negative linear relationship was weak $(r=-0.35)$. Also, there were non-significant correlations between duration of illness and executive functions assessed by Wisconsin card sorting test $(p>0.05)$, except for categories completed (reflecting abstract thinking) which exhibited statistically a significant correlation with duration of illness $(p<0.05)$ though this negative linear relationship was weak $(r=-0.28)$

Little is known about the pathophysiological events linking cognitive impairment and depression.

Therefore, our study aimed to evaluate cognitive deficits, in a sample of adult patients with MDD in remission state of their depressive symptoms through a crosssectional study carried out on persons attending Outpatient Psychiatric Clinics, Suez Canal University Hospital, Ismailia Governorate, Egypt. The mean age of patients was $33 \pm 8.2$ years, $77.7 \%$ were female, the average age at onset of MDD was $23.3 \pm 6.3$ years, the average duration of illness was $8.4 \pm 4.99$ years and the average number of depressive episodes was $3.87 \pm$ 1.96. Good matching in our study of the two studied groups ruled out confounding variables like age, sex, and education level (Tables 1 and 2). Patients group with MDD in remission in this study, compared to controls, showed a statistically significant decline in cognitive function regarding visual memory, verbal memory, attention/ concentration, and psychomotor speed (Table 3). Also there were statistically significant differences between patients and control group in executive function regarding trial administrated, categories completed and perseverative error (Table 4). This may be due to that cognitive dysfunctions associated with MDD can endure beyond
Table 6 Correlation between age at onset of MDD and cognitive and executive functions

\begin{tabular}{lll}
\hline & $\boldsymbol{r}$ & $\boldsymbol{P}$ \\
\hline Visual memory & -0.05 & $>0.05(\mathrm{NS})$ \\
$\quad$ Figural memory & 0.14 & $>0.05(\mathrm{NS})$ \\
$\quad$ Visual Paired Associates & & \\
Verbal memory & 0.14 & $>0.05(\mathrm{NS})$ \\
$\quad$ Logical memory & 0.11 & $>0.05(\mathrm{NS})$ \\
$\quad$ Verbal Paired Associates & & \\
Attention/concentration & $-\mathbf{0 . 1 8}$ & $>0.05(\mathrm{NS})$ \\
$\quad$ Mental control & $\mathbf{- 0 . 0 6}$ & $>0.05(\mathrm{NS})$ \\
$\quad$ Digit span & & \\
Visuospatial function & $\mathbf{- 0 . 0 7}$ & $>0.05(\mathrm{NS})$ \\
$\quad$ Visual reproduction & & \\
Wisconsin card sorting test & $\mathbf{0 . 0 8}$ & $>0.05(\mathrm{NS})$ \\
$\quad$ Trial administered (conceptualization) & $\mathbf{- 0 . 0 6}$ & $>0.05(\mathrm{NS})$ \\
Categories completed (abstract ability) & $\mathbf{- 0 . 1 5}$ & $>0.05(\mathrm{NS})$ \\
Perseverative errors (cognitive flexibility) & $\mathbf{- 0 . 1 3}$ & $>0.05(\mathrm{NS})$ \\
Failure to maintain set (sustained attention)
\end{tabular}

There were statistically non-significant correlations between age at onset of MDD and different subsets of Wechsler memory scale $(p>0.05)$. Also, there were non-significant correlations between age at onset of depression and executive function as assessed by Wisconsin card sorting test $(p>0.05)$

clinical symptom remission, limiting work functioning, and contributing to the overall disability [11].

In agreement with our study, Bortolato et al. studied cognitive in MDD patients and found cognitive dysfunction in several domains, such as executive function, memory, and attention. Therefore, they concluded that cognitive impairment persists during the remission as a residual manifestation in depression [12]. Cognitive impairments in memory, attention, and executive function in our study are consistent with a prospective cohort study that followed patients with MDD until remission. Another study examined subjects with major depressive disorder in remission found impairment in information processing speed and memory, and over half of the subjects had cognitive impairment [13].

Most of the studies of patients with MDD in remission concluded that there are impairment in different cognitive functions, such as sustained attention [3, 14], attention and executive functioning [15], verbal memory and verbal fluency $[16,17]$, and executive functioning [18$20]$ and thus make great indications that symptom reduction in MDD is not followed by cognitive improvement to a similar degree.

Our findings of memory impairment, attention problems, and executive dysfunction (deficits of conceptualization, abstract ability, and cognitive flexibility) are consistent with the study carried out by Oral et al., which determined that the executive 
functions, short and long-term memory, working memory, and attention performances of patients with MDD were lower than those of the healthy control group [21]. However, when Memory is studied in terms of explicit and implicit, it is stated that in depression there are no implicit memory problems because it is an automatic processes but the explicit memory affected because requires a recollection [22].

Many evidence reported that cognitive impairment are common both during and residually following depression [23, 24]. Moreover, individuals have reported impairment in cognitive function, even after remission of depressive symptoms, which affect the workplace productivity/performance, quality of life, and the global function [25]. A study found that patients who were currently in a state of remission for MDD experienced persistent cognitive deficits compared to control subjects [24]. The most cognitive deficits that remain after remission of depression are the attention and executive performance [15, 24].

Cognitive impairments persist during periods of remission even after treating MDD [26], which show the discrepancy between emotional and functional improvement. In our study, the relationship between depressive and cognitive profiles revealed that no significant correlations did exist between age at onset of MDD nor the duration of illness with different domains of cognitive function as assessed according to the standard scores of the applied tests except for figural memory (a subtest of verbal memory) of WMS-R and categories completed (reflecting abstract ability) of Wisconsin card sorting test which exhibited statistically high significant correlation with duration of illness (Tables 5 and 6). In agreement with our finding, Karabekiroglu et al. reported that the cumulative duration of depressive episodes and their repetition have effect on the severity of the associated-cognitive impairment [27].

Best et al. concluded that early-onset depression is associated with higher disease severity and with higher levels of recurrence [28]. Also Hasselbalch et al. stated that many factors are involved and affect the neurocognitive course in MDD (number, duration, severity of MDD episodes, age of onset, time passed since the last episode of depression, treatment interventions used, or co-existent psychiatric disorders), which makes the identification of a specific cognitive profile in remitted persons even more complex. The severity of cognitive impairment increases as a function of the cumulative duration of MDEs [29].

\section{Conclusions}

- In this study, patients with MDD in remission states showed deficits in several cognitive domains including visual memory, verbal memory, and attention/concentration/ psychomotor speed, together with deficits in executive functions including impaired conceptualization, impaired abstract ability, and less cognitive flexibility when compared to matched control subjects.

- Duration of depressive disorder showed significant correlations with impairment on some cognitive domains as figural memory and abstract ability.

- MDD patients in remission state may experience an improvement in some cognitive domains following antidepressant therapy, but do not reach normal levels of performance.

- Cognitive training and rehabilitation could prove important in treating depression and help preventing the relapse.

\section{Study limitations}

The present study had some limitations:

- Small sample size, non-probability sampling technique, and utilization of different antidepressant drugs are the most important limitations of this study.

- The reason for this is mainly ethical as most persons are taking medications regularly with difficulties in finding patients with MDD on no treatment, fulfilling the inclusion and exclusion criteria of the study, and being willing to participate.

- It was difficult to include patients taking the same antidepressant drugs.

- Assessment of the severity of MDD would have helped give more precise results.

\section{Abbreviation}

MDD: Major depressive disorder; Cl: Cognitive impairment; DSM-

IV: Diagnostic and Statistical Manual of Mental Disorders; MINI-plus: MiniInternational Neuropsychiatric Interview plus; WMS-R: Wechsler Memory Scale-Revised; WCST: Wisconsin Card Sorting Test

Acknowledgements

Delighted to thank all subjects who take part of the study or withdrawal.

Authors' contributions

Study conception and design: MF,WL, AT, and HH. Data collection: $\mathrm{HH}$ and MA. Data analysis and interpretation: $\mathrm{HH}$ and MA. Drafting of the article: $M F, W L, A T, H H$, and MA. Critical revision of the article: MF,WL, AT, and HH. The authors read and approved the final manuscript.

Funding

Spent by research team

Availability of data and materials

Available data and material

\section{Declarations}

\section{Ethics approval and consent to participate}

- An official letter for data collection was obtained from the head of ethics committee to start data collection in the Faculty of Medicine. 
- The objectives and aims of the study were clarified to the participants.

- The studied subjects were assured of maintaining anonymity and confidentiality of collected data.

- Informed written consent from both groups was obtained from both patients and the control group to participate in the study.

- The studied subjects were informed that they have the right to withdraw from the study at any time. Consent for publication: oral consent from the study subjects was obtained for publication.

\section{Consent for publication}

Oral consent from the study subjects was obtained for publication.

\section{Competing interests}

The authors declare that they have no competing interests.

Received: 16 August 2021 Accepted: 30 September 2021

Published online: 18 November 2021

\section{References}

1. Kessler RC, Berglund P, Demler O, Jin R, Koretz D, Merikangas KR, Rush AJ, Walters EE, Wang PS, Replication NCS (2003) The epidemiology of major depressive disorder: results from the national comorbidity survey replication (NCS-R). Jama 289(23):3095-3105. https://doi.org/10.1001/jama.289.23.3095

2. Whiteford HA, Ferrari AJ, Degenhardt L, Feigin V, Vos T (2015) The global burden of mental, neurological and substance use disorders: an analysis from the global burden of disease study 2010. PLoS One 10(2):e0116820. https://doi.org/10.1371/journal.pone.0116820

3. Majer $M$, Ising M, Künzel $H$, Binder $E$, Holsboer F, Modell $S$ et al (2004) Impaired divided attention predicts delayed response and risk to relapse in subjects with depressive disorders. Psychol Med 34(8):1453-1463. https:// doi.org/10.1017/S0033291704002697

4. Jaeger J, Berns S, Uzelac S, Davis-Conway S (2006) Neurocognitive deficits and disability in major depressive disorder. Psychiatry Res 145(1):39-48. https://doi.org/10.1016/j.psychres.2005.11.011

5. Douglas KM, Porter RJ (2009) Longitudinal assessment of neuropsychological function in major depression. Aust N Z J Psychiatry 43(12):1105-1117. https://doi.org/10.3109/00048670903279887

6. Wingenfeld $\mathrm{K}$ et al (2015) Effects of cortisol on cognition in major depressive disorder, post-traumatic stress disorder and borderline personality disorder. Psychoneuroendocrinology 51:282-295

7. Miskowiak KW, Ott CV, Petersen JZ, Kessing LV (2016) A systematic review of randomized controlled trials of candidate treatments for cognitive impairment in depression and methodological challenges in the field. Eur Neuropsychopharmacol. 26(12):1845-1867. https://doi.org/10.1016/j. euroneuro.2016.09.641

8. Sheehan DV, Lecrubier Y et al (1998) Reliability and validity of the MINI mini international neuropsychiatric interview. Eur Psychiatry. 12:232-241

9. Wechsler D (1987) The Wechsler Memory Scale-Revised: Psychological Corporation, New York

10. Heaton RK (1981) Wisconsin Card Sorting Test Manual. Psychologica Assessment Resources, Odessa, FL

11. Harvey PD, Jacobson W, Zhong W, Nomikos GG, Cronquist Christensen M, Kurre Olsen C et al (2017) Determination of a clinically important difference and definition of a responder threshold for the UCSD performance-based skills assessment (UPSA) in patients with major depressive disorder. J Affect Disord 213:105-111. https://doi.org/10.1016/j.jad.2017.02.014

12. Bortolato B et al (2017) Cognitive remission: a novel objective for the treatment of major depression. BMC Med. 2016 Jan 22(14):9

13. Defrancesco M et al (2009) Association of mild cognitive impairment (MCl) and depression. Neuropsychiatry 23(3):144-150

14. Weiland-Fiedler P, Erickson K, Waldeck T, Luckenbaugh DA, Pike D, Bonne O, Charney DS, Neumeister A (2004) Evidence for continuing neuropsychological impairments in depression. J. Affect. Disord. 82(2):253258. https://doi.org/10.1016/j.jad.2003.10.009

15. Paelecke-Habermann Y, Pohl J, Leplow B (2005) Attention and executive functions in remitted major depression patients. J. Affect. Disord. 89(1-3): 125-135. https://doi.org/10.1016/j.jad.2005.09.006

16. Reischies FM, Neu P (2000) Comorbidity of mild cognitive disorder and depression - a neuropsychological analysis. Eur. Arch. Psychiatry Clin. Neurosci. 250(4):186-193. https://doi.org/10.1007/s004060070023
17. Neu P, Bajbouj M, Schilling A, Godemann F, Berman R, Schlattmann P (2005) Cognitive function over the treatment course of depression in middle-aged patients: correlation with brain MRI signal hyperintensities. J. Psychiatr. Res. 39(2):129-135. https://doi.org/10.1016/j.jpsychires.2004.06.004

18. Smith DJ, Muir WJ, Blackwood DH (2006) Neurocognitive impairment in euthymic young adults with bipolar spectrum disorder and recurrent major depressive disorder. Bipolar Disord. 8(1):40-46. https://doi.org/10.1111/j.13 99-5618.2006.00275.x

19. Gruber S, Rathgeber K, Braunig P, Gauggel S (2007) Stability and course of neuropsychological deficits in manic and depressed bipolar patients compared to patients with major depression. J. Affect. Disord. 104(1-3):6171. https://doi.org/10.1016/j.jad.2007.02.011

20. Reppermund S, Ising M, Lucae S, Zihl J (2009) Cognitive impairment in unipolar depression is persistent and non-specific: further evidence for the final common pathway disorder hypothesis. Psychol. Med. 39(4):603-614. https://doi.org/10.1017/S003329170800411X

21. Oral E, Canpolat S, Yildirim S, Gulec M, Aliyev E, Aydin N (2012) Cognitive functions and serum levels of brain-derived neurotrophic factor in patients with major depressive disorder. Brain Res Bull. 88(5):454-459. https://doi. org/10.1016/j.brainresbull.2012.03.005

22. Karabekiroğlu K, Gımzal A, Berkem M (2005) Psikiyatrik bozukluklardabellek sorunları. Anatolian Journal of Psychiatry 6:188-196

23. Mclntyre RS, Cha DS, Soczynska JK, Woldeyohannes HO, Gallaugher LA, Kudlow P et al (2013) Cognitive deficits and functional outcomes in major depressive disorder: determinants, substrates, and treatment interventions. Depress Anxiety. 30(6):515-527. https://doi.org/10.1002/da.22063

24. Preiss M, Kucerova H, Lukavsky J, Stepankova H, Sos P, Kawaciukova R (2009) Cognitive deficits in the euthymic phase of unipolar depression. Psychiatry Res 169(3):235-239. https://doi.org/10.1016/j.psychres.2008.06.042

25. Mclntyre RS, Soczynska JZ, Woldeyohannes HO, Alsuwaidan MT, Cha DS, Carvalho AF et al (2015) The impact of cognitive impairment on perceived workforce performance: results from the international mood disorders collaborative project. Comprehens Psychiatry 56:279-282. https://doi.org/1 0.1016/j.comppsych.2014.08.051

26. McIntyre RS, Xiao HX, Syeda K, Vinberg M, Carvalho AF, Mansur RB et al (2015) The prevalence, measurement, and treatment of the cognitive dimension/domain in major depressive disorder. CNS Drugs 29(7):577-589. https://doi.org/10.1007/s40263-015-0263-x

27. Karabekiroglu A, Topcuoglu V, Gimzal Gonentur A, Karabekiroglu K (2010) Executive function differences between first episode and recurrent major depression patients. Turk Psikiyatri Derg 21(4):280-288

28. Best JR, Miller PH, Naglieri JA (2011) Relations between executive function and academic achievement from ages 5 to 17 in a large, representative national sample. Learn. Individ. Differ 21(4):327-336. https://doi.org/10.1016/ j.lindif.2011.01.007

29. Hasselbalch BJ (2015) Cognition and neuroplasticity in the remitted state of unipolar depressive disorder. Dan. Med. J. 62:B5080

\section{Publisher's Note}

Springer Nature remains neutral with regard to jurisdictional claims in published maps and institutional affiliations.

\section{Submit your manuscript to a SpringerOpen ${ }^{\circ}$ journal and benefit from:}

- Convenient online submission

- Rigorous peer review

- Open access: articles freely available online

High visibility within the field

- Retaining the copyright to your article

Submit your next manuscript at $>$ springeropen.com 